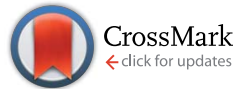

Cite this: Chem. Sci., 2016, 7, 4720

Received 11th March 2016

Accepted 9th April 2016

DOI: $10.1039 / \mathrm{c} 6 \mathrm{sc} 01133 \mathrm{k}$

www.rsc.org/chemicalscience

\section{The third orthogonal dynamic covalent bond $\dagger$}

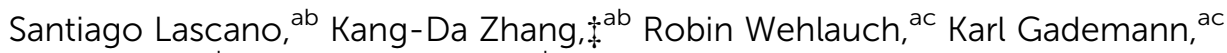 \\ Naomi Sakai ${ }^{\text {ab }}$ and Stefan Matile*ab
}

\begin{abstract}
Orthogonal dynamic covalent bonds are of interest for the construction of functional systems. The orthogonality of disulfide and hydrazone exchange under basic and acidic conditions, respectively, is well established. However, the integration of boronate esters as the third bond has failed so far because they exchanged too easily, especially under hydrazone exchange conditions. In this report, a collection of bioinspired catechols derived from adhesive natural products from cyanobacteria is screened with phenylboronic acids with proximal alcohols (benzoboroxoles), amines and fluorines to identify the least labile boronate esters. Moreover, Kool's 2-aminophenol catalysts are introduced to selectively accelerate hydrazone exchange without disturbing sufficiently inert boronate esters. Based on these results, we identified three different conditions to selectively exchange disulfides, hydrazones and boronate esters, that is to demonstrate the existence of three orthogonal dynamic covalent bonds. Moreover, their compatibility with functional systems is confirmed by successful hydrazone exchange in multicomponent surface architectures in the presence of intact boronate esters and disulfides.
\end{abstract}

Dynamic covalent bonds are fascinating because they can be either as stable as covalent bonds or as rapidly exchanging as non-covalent bonds, depending on the conditions. ${ }^{\mathbf{1 - 4}}$ This dual nature makes them ideal tools for the construction of multicomponent functional systems. However, contrary to the routine use of several non-covalent bonds at the same time, dynamic covalent bonds are usually used alone. This could be in part due to the poor orthogonality between different types of dynamic covalent bonds. Orthogonality is defined by the existence of conditions that allow the exchange of one without disturbing the others (Fig. 1). The most popular pair of orthogonal dynamic bonds, hydrazones ${ }^{2}$ and disulfides ${ }^{3}$ exchange exclusively under acidic and basic conditions, respectively, and thus enabled the construction and operation of various doubly dynamic functional systems. ${ }^{5-8}$

Extending this approach, triply dynamic functional systems have been constructed very recently ${ }^{\mathbf{9} 10}$ with boronate esters, ${ }^{1}$ hydrazones and disulfides. These studies have shown the feasibility to exchange boronate esters in the presence of intact hydrazones and disulfides ${ }^{9}$ and to simultaneously form these

${ }^{a}$ National Centre of Competence in Research (NCCR), Molecular Systems Engineering (MSE), Switzerland; Web: http://www.nccr-mse.ch

${ }^{b}$ Department of Organic Chemistry, University of Geneva, Geneva, Switzerland. E-mail: stefan.matile@unige.ch; Web: http://www.unige.ch/sciences/chiorg/matile/; Fax: +41 22379 5123; Tel: +41223796523

${ }^{c}$ Department of Chemistry, University of Zurich, Zurich, Switzerland

$\dagger$ Electronic supplementary information (ESI) available: Detailed procedures and results for all reported experiments. See DOI: 10.1039/c6sc01133k

\$ Present address: Department of Chemistry, Zhejiang Normal University, Jinhua, China. three types of bonds. ${ }^{\mathbf{1 0}}$ However, the orthogonality of boronate esters as the third dynamic covalent bond could not be established so far because (a) they are too labile, particularly under acidic conditions, and (b) hydrazone exchange requires strong acids. ${ }^{9,10}$ To overcome this dilemma, we first considered the use of electron-deficient catechol derivatives of anachelin, a natural product from the cyanobacterium Anabaena cylindrica. The high affinity of these bioinspired catechols to mineral oxides ${ }^{\mathbf{1 1}}$ suggested that they might also afford more inert boronate esters. To overcome the second obstacle en route to the third orthogonal organic dynamic covalent bond, weakening of the hydrazone bond was not an option because it would destabilize the entire functional system. ${ }^{12}$ Acceleration of the exchange of inert aryl hydrazones appeared more promising, also because the original aniline catalysts ${ }^{\mathbf{1 3}}$ have been dramatically improved recently with bifunctional acid/base catalysts. ${ }^{14-16}$ The anthranilic acids ${ }^{\mathbf{1 5}}$ and, more interestingly, the 2-aminophenols ${ }^{\mathbf{1 6}}$ are thought to operate by intramolecular protonation of the $\mathrm{OH}$

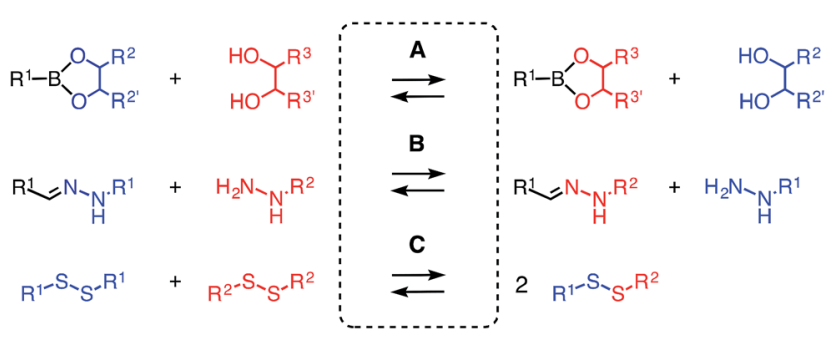

Fig. 1 Selective exchange under conditions A, B and C defines orthogonality of disulfides, hydrazones and boronic/boronate esters. 
leaving group via 8- and 7-membered rings, respectively, to accelerate the rate-limiting dehydration during hydrazone formation from aldehydes and hydrazines. Contemplating this elegant catalyst design, we felt that the proposed mechanism could also extend to the activation of the $\mathrm{NH}$ leaving group during hydrazone exchange. In the following, we show that indeed the combination of bioinspired catechol adhesives ${ }^{11}$ and cutting-edge organocatalysts ${ }^{\mathbf{1 6}}$ was the key to find the third orthogonal dynamic covalent bond.

Catechols 1-9 were chosen for this study (Fig. 2) and the protected anachelin chromophore $\mathbf{5}^{\mathbf{1 1}}$ served as starting point for the design of catechols. Recognizing the power of electrondeficient aromatic units, we prepared new catecholate derivatives 2, 7-9 for subsequent experiments. Phenylboronic acids 10-12 with proximal primary alcohols (benzoboroxoles), ${ }^{\mathbf{1 7}}$ tertiary amines ${ }^{\mathbf{1 c}, \mathbf{1 8}}$ and fluorines ${ }^{7}$ have been reported previously. The formation of boronate esters was assessed in $\mathrm{MeOH} /$ water $3: 1$, pH 7.8, at room temperature (Fig. S1 and $2 \dagger$ ). Changes in the absorption spectra of catechols, kept constant at low micromolar concentrations, were recorded in response to increasing concentrations of boronic acids. Reverse titration of boronate esters of alizarin red 4 provided access to the $K_{\mathrm{D}}$ 's of otherwise "invisible" catechols.

Compared to the previous best performing catechols 3, 4 and 6, the most distinctive results with the new "bioadhesives" 1, 2, 5 and 7-9 were obtained with benzoboroxoles 10 (Fig. 2, Table $\mathrm{S} 1 \dagger)$. As on oxide surfaces, ${ }^{11}$ nitrodopamine 1 with a $K_{\mathrm{D}}=280$ $\mu \mathrm{M}$ was best also with regard to boronate ester formation. It was

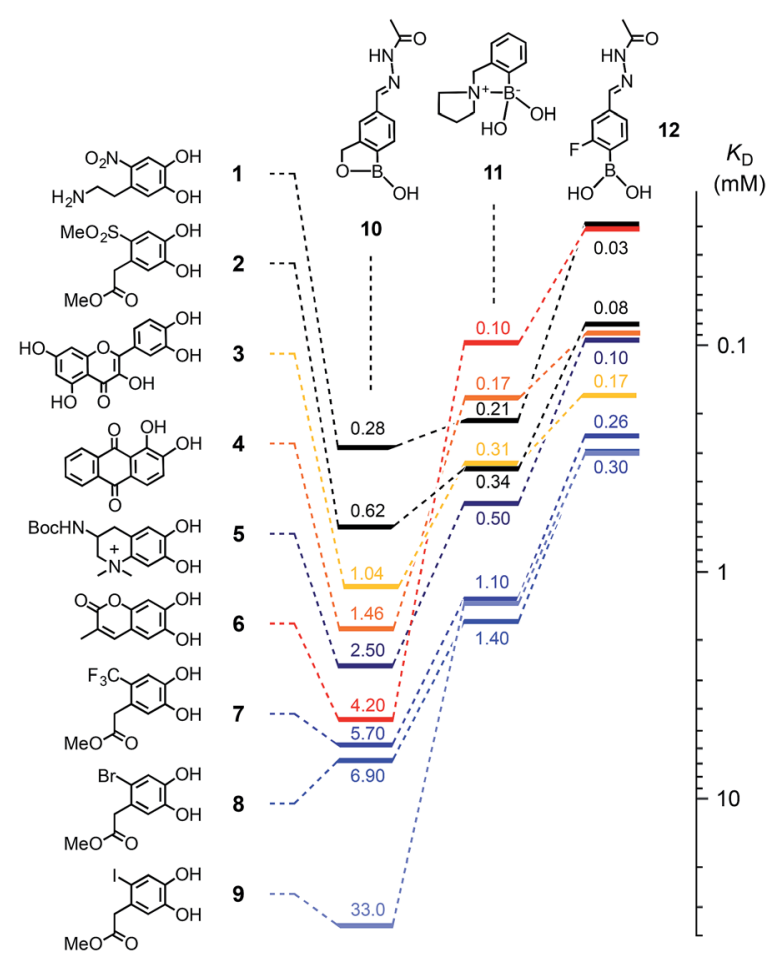

Fig. 2 Dissociation constants $K_{\mathrm{D}}(\mathrm{mM})$ of boronic esters obtained from catechols 1-9 and boronic acids $10-12$ in $\mathrm{MeOH} / \mathrm{H}_{2} \mathrm{O} 3: 1$ (100 $\mathrm{mM}$ HEPES, $\mathrm{pH}$ 7.8); from changes in absorption upon direct titration $(1,3,4$ and 6$)$ or reverse titration with $4(2,5,7-9)$. followed by the similarly electron-deficient methyl sulfone 2 at $620 \mu \mathrm{M}$, quercetin 3 and alizarin red 4 as the first positive controls at 1.04 and $1.46 \mathrm{mM}$, and the close anachelin mimic 5 at $2.50 \mathrm{mM}$. "Bioadhesives" 2, 5 and particularly 1 also gave top values with the fluorinated boronic acid 12, whereas boronic acid $\mathbf{1 1}$ was overall slightly less convincing with anachelin mimics, particularly 1.

The outstanding $K_{\mathrm{D}}$ 's of the new "bioadhesives" 1 and 2 with benzoboroxole 10 were most important because boronate esters of benzoboroxoles have been identified previously as best in functional systems, presumably because the less electrophilic tetrahedral boronate is intramolecularly stabilized. ${ }^{9}$ Testifying its inertness, the boronate ester 13, prepared from the best performing anachelin mimic $\mathbf{1}$ and 10, underwent only marginal exchange with catechol 8 to boronate $\mathbf{1 4}$ under acidic hydrazone exchange conditions $\mathbf{B}$ (around 10\%, see below,

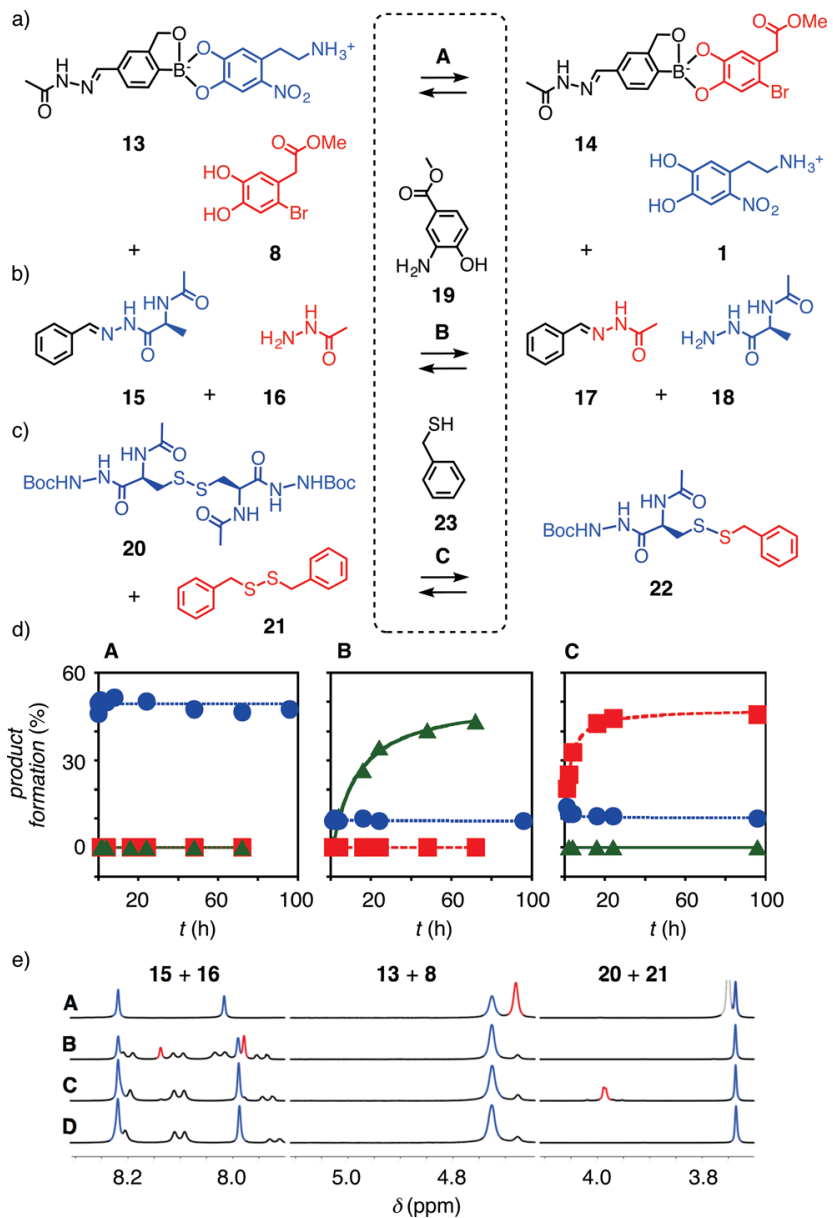

Fig. 3 (a-c) Exchange reactions used in this study to identify orthogonality under conditions A, B and C. (d) Exchange kinetics for boronate esters ( $\bullet, 20 \mathrm{mM}$ 13, $22 \mathrm{mM}$ 8) hydrazones ( $\Lambda, 20 \mathrm{mM} \mathrm{15,20}$ $\mathrm{mM} 16)$ and disulfides $(\square, 20 \mathrm{mM} 20,20 \mathrm{mM} 21)$ under conditions $A$ (DMSO- $d_{6}, 10 \% \mathrm{D}_{2} \mathrm{O}, 2 \%$ DIPEA), B (1.0 mM 19, $1.5 \mathrm{mM}$ TFA in DMSO$\left.d_{6}\right)$, and $C\left(2.0 \mathrm{mM} 22,2.0 \mathrm{mM}\right.$ TEA in DMSO- $\left.d_{6}\right)$. (e) Original data showing diagnostic peaks in ${ }^{1} \mathrm{H}$ NMR spectra in conditions $A-C$ and $D$ $\left(\mathrm{DMSO}-d_{6}\right.$ ) of 15, 20 and 13 (blue peaks) and their exchange products (red peaks). The signals at $\sim 8.1 \mathrm{ppm}$ disappear in conditions $\mathrm{A}$ due to $H / D$ exchange. 
Fig. 3a, dB $\bullet$ and $\mathrm{eB}$ ). In contrast, the exchange reached around $35 \%$ when replacing nitrodopamine $\mathbf{1}$ with anachelin $\mathbf{5}$ (Fig. S20 and 21†).

According to the kinetics measurements using ${ }^{1} \mathrm{H}$ NMR spectroscopy, the exchange reaction of boronate ester 13 with the catechol 8 in DMSO- $d_{6}$ containing $10 \% \mathrm{D}_{2} \mathrm{O}$ and $2 \%$ Hünig base, i.e., conditions $\mathbf{A}$, reached the equilibrium rapidly with a $t_{50}<3$ minutes (Table 1 , entry 1 , Fig. 3a, dA ๑, eA (red peak) and $\mathrm{S} 4 \dagger$ ). The result was a mixture of $\mathbf{1 3}$ and $\mathbf{1 4}$ at a ratio of $1: 1.1$. Reactivity in pure DMSO- $d_{6}$ (condition D, Fig. $3 \mathrm{e}$ ) and the other conditions $\mathbf{B}$ and $\mathbf{C}$ was low (Fig. $3 \mathrm{a}, \mathrm{dB} \bullet \mathrm{dC} \bullet \mathrm{e}, \mathrm{eB}$ and $\mathrm{C}$, S3-7†). Thus, standard boronate exchange conditions were already compatible with hydrazone and disulfide bonds.

It was difficult to identify the hydrazone exchange conditions compatible with the other two dynamic covalent bonds. Boronate ester $\mathbf{1 3}$ hydrolyzed quickly and completely under the acidic hydrazone exchange conditions even with aniline $\mathrm{e}^{\mathbf{1 3 - 1 5}}$ or with the recent anthranilic acid catalysts, ${ }^{15}$ because the necessary amounts of acid and catalysts were excessive (Fig. S19†). However, 2-aminophenol 19, acidified by a withdrawing ester in position $4,{ }^{16}$ catalyzed hydrazone exchange with a $t_{50}=11.9 \mathrm{~h}$ to reach equilibrium at a ratio $\mathbf{1 5} / \mathbf{1 7}=1.3: 1$ under condition $\mathbf{B}$ (Fig. $3 \mathrm{~b}, \mathrm{~dB} \Delta$, eB (red peaks), S10†; Table 1, entry 2). Most importantly, the ${ }^{1} \mathrm{H}$ NMR spectrum of boronate ester 13 did not change much under condition $\mathbf{B}$, and disulfides were not affected either (Fig. 3dB e, $\square$, eB, S9-13†, Table 1).

To complete the series needed to demonstrate the existence of the third orthogonal dynamic covalent bond, disulfide exchange from substrates 20 and 21 to mixed product 22 and back was initiated with traces of thiol 23 . Under condition $\mathbf{C}$, equilibrium was reached with $t_{50}=2.5 \mathrm{~h}$ at a ratio of $\mathbf{2 0} / \mathbf{2 2}=$ 1 : 1.6 (Fig. 3c, dC $\mathrm{n}$, eC (red peak)), without disturbing hydrazones and boronate esters (Fig. 3dC $\Delta, \bullet$, eC, S14-18†; Table 1, entry 3).

Compatibility of the third orthogonal dynamic covalent bond with functional systems was explored with multicomponent surface architecture 24 (Fig. 4). This system was obtained by the well-established SOSIP-TSE method (SOSIP = self-organizing surface-initiated polymerization; TSE $=$ templated stack exchange, Fig. S22 $\dagger){ }^{8,9}$ Namely, ring opening disulfide exchange polymerization was initiated by the thiolate groups bound on an indium-tin oxide (ITO) surface to yield, after the removal of benzaldehyde protecting group, the architecture 25. Reaction of boroxole aldehyde $10^{*}$ in $\mathrm{DMSO} / \mathrm{AcOH}$ with the hydrazides along the central stacks in $\mathbf{2 5}$ gave surface architecture $\mathbf{2 6}$.

Table 1 Orthogonal exchange kinetics ${ }^{a}$

\begin{tabular}{lllll}
\hline & & $t_{50}{ }^{b}(\mathrm{~h})$ & & \\
\cline { 3 - 5 } & Exchange & $\mathbf{A}$ & $\mathbf{B}$ & $\mathbf{C}$ \\
\hline 1 & Boronate & $<0.05$ & - & - \\
2 & Hydrazone & - & 11.9 & - \\
3 & Disulfide & - & - & 2.5
\end{tabular}

${ }^{a}$ See Fig. 3 for structures, conditions and original data. ${ }^{b}$ Half-life of substrates to reach equilibrium under conditions $\mathbf{A}, \mathbf{B}$ and $\mathbf{C}$.
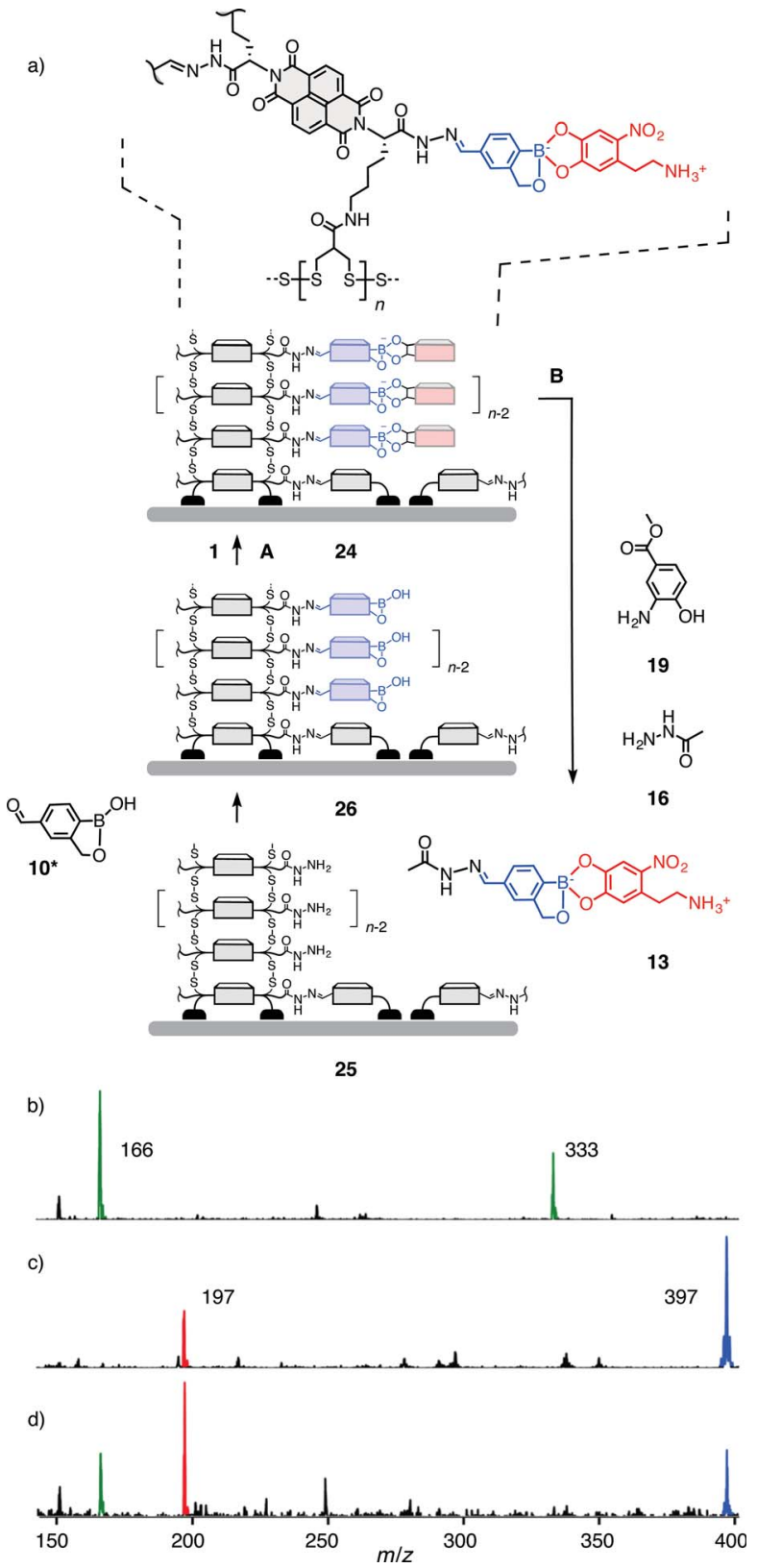

Fig. 4 (a) Synthesis of architecture 24 and subsequent recovery of intact boronate ester 13 by orthogonal hydrazone exchange, as evidenced by ESI-MS (negative mode) of (b) catalyst 19 ( $\mathrm{m} / \mathrm{z} 166$ ([M $\left.\left.\mathrm{H}]^{-}\right), 333\left([2 \mathrm{M}-\mathrm{H}]^{-}\right)\right)$, (c) $13\left(\mathrm{~m} / \mathrm{z} 397\left([\mathrm{M}-\mathrm{H}]^{-}\right)\right)$and catechol $1(\mathrm{~m} / \mathrm{z}$ $\left.197\left([\mathrm{M}-\mathrm{H}]^{-}\right)\right)$, and (d) the solution obtained from incubation of multicomponent surface architecture 24 with hydrazide 16 and 1.0 $\mathrm{mM}$ catalyst 19 in DMSO- $d_{6}, 1.5 \mathrm{mM} \mathrm{TFA}$, for $7 \mathrm{~h}$ at $40{ }^{\circ} \mathrm{C}(10: \mathrm{m} / \mathrm{z} 217$ $\left.\left([\mathrm{M}-\mathrm{H}]^{-}\right)\right)$.

Incubation of electrode 26 in a solution of nitrodopamine $\mathbf{1}$ in DMSO/Hünig base afforded the desired multicomponent architecture 24 .

While the orthogonal formation of three dynamic covalent bonds has been demonstrated for the construction of this system $^{9}$ and others, ${ }^{10}$ true orthogonality in functional systems, i.e., selective exchange, cleavage and formation of one bond without disturbing the others, remained to be demonstrated. 
The so far missing piece of evidence was hydrazone exchange in the presence of intact boronate esters. With the multicomponent surface architecture $\mathbf{2 4}$, this translated to the task to release intact boronate ester $\mathbf{1 3 .} .^{19}$ To tackle this challenge, the conditions $\mathbf{B}$ elaborated above for selective hydrazone exchange were applied (20 mM hydrazide 16, $1.0 \mathrm{mM}$ catalyst 19, $1.5 \mathrm{mM}$ TFA in DMSO- $d_{6}$ ). Because of the small amounts of material present per electrode, the same exchange solution was used for multiple electrodes (10 electrodes for $0.5 \mathrm{~mL}$ of solution). ${ }^{1} \mathrm{H}$ NMR of the obtained exchange solution showed the diagnostic peak of the boronate ester 13 at $4.72 \mathrm{ppm}$ and only a small peak of the hydrolysed benzoboroxole 10 at 5.01 ppm (Fig. S24 $\dagger$ ). Corroborative evidence for the release of intact ester $\mathbf{1 3}$ was obtained by ESI-MS (Fig. 4, S25 $\dagger$ ). These results identify the multicomponent surface architecture $\mathbf{2 4}$ as the first functional system that operates with three fully orthogonal organic ${ }^{20}$ dynamic covalent bonds, to the best of our knowledge. The insights gained here will be important for future developments in the construction of dynamic functional systems, and lead to the tantalizing question of the possible existence of a fourth orthogonal organic dynamic covalent bond.

\section{Acknowledgements}

We thank the NMR and the Sciences Mass Spectrometry (SMS) platforms for services, and the University of Geneva, the European Research Council (ERC Advanced Investigator), the Swiss National Centre of Competence in Research (NCCR) Molecular Systems Engineering, the NCCR Chemical Biology and the Swiss NSF for financial support.

\section{Notes and references}

1 (a) X. Wu, Z. Li, X.-X. Chen, J. S. Fossey, T. D. James and Y.-B. Jiang, Chem. Soc. Rev., 2013, 42, 8032-8048; (b) T. D. James, K. R. A. S. Sandanayake and S. Shinkai, Angew. Chem., Int. Ed., 1996, 35, 1910-1922; (c) S. L. Wiskur and E. V. Anslyn, J. Am. Chem. Soc., 2001, 123, 10109-10110; (d) W. Niu, M. D. Smith and J. J. Lavigne, J. Am. Chem. Soc., 2006, 128, 16466-16467; (e) M. Li, N. Lin, Z. Huang, L. Du, C. Altier, H. Fang and B. Wang, J. Am. Chem. Soc., 2008, 130, 12636-12638; $(f)$ G. Zhang, O. Presly, F. White, I. M. Oppel and M. Mastalerz, Angew. Chem., Int. Ed., 2014, 53, 5126-5130; $(g)$ N. Luisier, K. Schenk and K. Severin, Chem. Commun., 2014, 50, 10233-10236; $(h)$ B. Akgun and D. G. Hall, Angew. Chem., Int. Ed., 2016, 55, 3909-3913.

2 (a) O. Ramström, S. Lohmann, T. Bunyapaiboonsri and J.-M. Lehn, Chem.-Eur. J., 2004, 10, 1711-1715; (b) J. M. Poolman, J. Boekhoven, A. Besselink, A. G. L. Olive, J. H. van Esch and R. Eelkema, Nat. Protoc., 2014, 9, 977988; (c) T. Takeuchi, J. Montenegro, A. Hennig and S. Matile, Chem. Sci., 2011, 2, 303-307; (d) X. Su and I. Aprahamian, Chem. Soc. Rev., 2014, 43, 1963-1981; (e) C. S. Mahon, M. A. Fascione, C. Sakonsinsiri, T. E. McAllister, W. Bruce Turnbull and D. A. Fulton, Org. Biomol. Chem., 2015, 13, 2756-2761.
3 (a) H. Y. Au-Yeung, F. B. L. Cougnon, S. Otto, G. D. Pantoş and J. K. M. Sanders, Chem. Sci., 2010, 1, 567-574; (b) E.-K. Bang, M. Lista, G. Sforazzini, N. Sakai and S. Matile, Chem. Sci., 2012, 3, 1752-1763; (c) N. K. P. Samuel, M. Singh, K. Yamaguchi and S. L. Regen, J. Am. Chem. Soc., 1985, 107, 42-47; (d) R. Singh and G. M. Whitesides, J. Am. Chem. Soc., 1990, 112, 1190-1197; (e) A. G. Torres and M. J. Gait, Trends Biotechnol., 2012, 30, 185-190; (f) D. Basak, R. Kumar and S. Ghosh, Macromol. Rapid Commun., 2014, 35, 1340-1344; (g) D. Oupický and J. Li, Macromol. Biosci., 2014, 14, 908-922; (h) L. Monnereau, M. Nieger, T. Muller and S. Bräse, Adv. Funct. Mater., 2014, 24, 1054-1058; (i) C. Wang, M. R. Krause and S. L. Regen, J. Am. Chem. Soc., 2015, 137, 664-666; (j) M. Lista, J. Areephong, N. Sakai and S. Matile, J. Am. Chem. Soc., 2011, 133, 15228-15231; (k) G. Gasparini, E.-K. Bang, G. Molinard, D. V Tulumello, S. Ward, S. O. Kelley, A. Roux, N. Sakai and S. Matile, J. Am. Chem. Soc., 2014, 136, 6069-6074; (l) P.-T. Skowron, M. Dumartin, E. Jeamet, F. Perret, C. Gourlaouen, A. Baudouin, B. Fenet, J.-V. Naubron, F. Fotiadu, L. Vial and J. Leclaire, J. Org. Chem., 2016, 81, 654-661.

4 (a) J. Li, P. Nowak and S. Otto, J. Am. Chem. Soc., 2013, 135, 9222-9239; (b) J.-M. Lehn, Top. Curr. Chem., 2011, 322, 132; (c) E. Moulin, G. Cormos and N. Giuseppone, Chem. Soc. Rev., 2012, 41, 1031-1049; (d) Y. Jin, C. Yu, R. J. Denman and W. Zhang, Chem. Soc. Rev., 2013, 42, 6634-6654; (e) S. Zarra, D. M. Wood, D. A. Roberts and J. R. Nitschke, Chem. Soc. Rev., 2015, 44, 419-432; (f) A. Herrmann, Chem. Soc. Rev., 2014, 43, 1899-1933; $(g)$ S. J. Rowan, S. J. Cantrill, G. R. L. Cousins, J. K. M. Sanders and J. F. Stoddart, Angew. Chem., Int. Ed., 2002, 41, 898-952.

5 A. Wilson, G. Gasparini and S. Matile, Chem. Soc. Rev., 2014, 43, 1948-1962.

6 (a) H. H. Jo, R. Edupuganti, L. You, K. N. Dalby and E. V Anslyn, Chem. Sci., 2015, 6, 158-164; (b) A. G. Campaña, D. A. Leigh and U. Lewandowska, J. Am. Chem. Soc., 2013, 135, 8639-8645; (c) J. F. Teichert, D. Mazunin and J. W. Bode, J. Am. Chem. Soc., 2013, 135, 11314-11321; (d) K. D. Okochi, Y. Jin and W. Zhang, Chem. Commun., 2013, 49, 4418-4420; (e) B. Icli, E. Solari, B. Kilbas, R. Scopelliti and K. Severin, Chem.-Eur. J., 2012, 18, 14867-14874; (f) M. J. Barrell, A. G. Campaña, M. von Delius, E. M. Geertsema and D. A. Leigh, Angew. Chem., Int. Ed., 2011, 50, 285-290; $(g)$ Z. Rodriguez-Docampo and S. Otto, Chem. Commun., 2008, 42, 5301-5303; $(h)$ A. G. Orrillo, A. M. Escalante and R. L. E. Furlan, Chem. Commun., 2008, 42, 5298-5300; (i) N. Christinat, R. Scopelliti and K. Severin, Angew. Chem., Int. Ed., 2008, 47, 1848-1852; (j) Y. Pérez-Fuertes, A. M. Kelly, A. L. Johnson, S. Arimori, S. D. Bull and T. D. James, Org. Lett., 2006, 8, 609-612; (k) H. Hayashi, A. Sobczuk, A. Bolag, N. Sakai and S. Matile, Chem. Sci., 2014, 5, 4610-4614.

7 S. Hagihara, H. Tanaka and S. Matile, J. Am. Chem. Soc., 2008, 130, 5656-5657.

8 N. Sakai and S. Matile, J. Am. Chem. Soc., 2011, 133, 1854218545. 
9 (a) K.-D. Zhang and S. Matile, Angew. Chem., Int. Ed., 2015, 54, 8980-8983; (b) K.-D. Zhang, N. Sakai and S. Matile, Org. Biomol. Chem., 2015, 13, 8687-8694.

10 L. Rocard, A. Berezin, F. De Leo and D. Bonifazi, Angew. Chem., Int. Ed., 2015, 54, 15739-15743.

11 (a) K. Gademann, Acc. Chem. Res., 2015, 48, 731-739; (b) S. Zürcher, D. Wäckerlin, Y. Bethuel, B. Malisova, M. Textor, S. Tosatti and K. Gademann, J. Am. Chem. Soc., 2006, 128, 1064-1065; (c) B. Malisova, S. Tosatti, M. Textor, K. Gademann and S. Zürcher, Langmuir, 2010, 26, 40184026.

12 (a) R. Nguyen and I. Huc, Chem. Commun., 2003, 39, 942-943; (b) S. R. Beeren, M. Pittelkow and J. K. M. Sanders, Chem. Commun., 2011, 47, 7359-7361.

13 (a) E. H. Cordes and W. P. Jencks, J. Am. Chem. Soc., 1962, 84, 826-831; (b) A. Dirksen, S. Dirksen, T. M. Hackeng and P. E. Dawson, J. Am. Chem. Soc., 2006, 128, 15602-15603.

14 (a) M. Wendeler, L. Grinberg, X. Wang, P. E. Dawson and M. Baca, Bioconjugate Chem., 2014, 25, 93-101; (b) M. Rashidian, M. M. Mahmoodi, R. Shah, J. K. Dozier,
C. R. Wagner and M. D. Distefano, Bioconjugate Chem., 2013, 24, 333-342.

15 (a) E. T. Kool, D. Park and P. Crisalli, J. Am. Chem. Soc., 2013, 135, 17663-17666; (b) E. T. Kool, P. Crisalli and K. M. Chan, Org. Lett., 2014, 16, 1454-1457.

16 D. Larsen, M. Pittelkow, S. Karmakar and E. T. Kool, Org. Lett., 2015, 17, 274-277.

17 (a) M. Bérubé, M. Dowlut and D. G. Hall, J. Org. Chem., 2008, 73, 6471-6479; (b) G. A. Ellis, M. J. Palte and R. T. Raines, J. Am. Chem. Soc., 2012, 134, 3631-3634.

18 M. Li, S. Ishihara, M. Akada, M. Liao, L. Sang, J. P. Hill, V. Krishnan, Y. Ma and K. Ariga, J. Am. Chem. Soc., 2011, 133, 7348-7351.

19 Intact poly(disulfide)s during hydrazone exchange, also under hasher conditions, is the basis of all functional studies realized so far with these systems. ${ }^{5,6 k, 8,9}$

20 In this study, inorganic coordination chemistry is not considered. Compare, for example: R. J. Sarma, S. Otto and J. R. Nitschke, Chem.-Eur. J., 2007, 13, 9542-9546. 